\title{
Transformative Experience in Skepticism. The External Standpoint and the Finitude of the Human Condition
}

\author{
RICO GUTSCHMIDT
}

\begin{abstract}
According to its quietist readings, skepticism can be dissolved by demonstrating that the notion of 'absolute objectivity' is confused. The dissolution of this confusion is supposed to lead us to acquiesce in our finite and plain everyday life without being bothered anymore about the supposed need for objective knowledge. In contrast, I want to propose a transformative reading of skepticism according to which the philosophical practice of skepticism can be 'epistemically transformative'. To this end, I will transpose L.A. Paul's notion of 'epistemically transformative experience' from decision theory to the realm of philosophical practice and argue that the modern skeptical problem of an external standpoint can evoke transformative experiences that lead to a new, albeit non-propositional, insight into the finitude of the human condition.
\end{abstract}

\section{Introduction}

In its deepest and historically most influential forms, skepticism is best understood as a philosophical practice that leads to a transformation of the self. This idea finds its original sources in ancient skepticism and reasserts itself in a variety of guises throughout the subsequent centuries. However, transformative accounts of skepticism are usually understood as a form of quietism, since they are supposed to bring us back to where we were in our everyday lives before we got disturbed by philosophical questions. More precisely, according to quietist readings, the philosophical practice of skepticism shows us that, for example, the notion of 'absolute objectivity' is confused. The dissolution of this confusion leads us to acquiesce in our finite and plain everyday life without being bothered anymore about the supposed need for objective knowledge.

Against this quietist reading, I want to propose a transformative reading of skepticism according to which the philosophical practice of skepticism can be 'epistemically transformative'. To this end, I will transpose L.A. Paul's notion of 'epistemically transformative 


\section{Rico Gutschmidt}

experience' from decision theory to the realm of philosophical practice and argue that the modern skeptical problem of an external standpoint can evoke transformative experiences that lead to a new, albeit non-propositional, insight into the finitude of the human condition. This insight, one might put it, is not so much abstractly understood as it is concretely experienced. In particular, it does not have the form of a theoretical statement. The insight into the finitude of the human condition is not captured, for example, by the statement that we cannot have an absolutely objective perspective on the world. Rather, on my reading, human finitude is such that we cannot even coherently think of such a 'view from nowhere' and that this revelation - this inability to conceive of the idea of an 'external standpoint' - leads to vertiginous experiences that are epistemically transformative with respect to our finitude. In other words, I will argue that these experiences bring about a new way of being and seeing against the background of the incomprehensibility of the notion of an 'external standpoint'.

This result will be established in three steps. In the first step, I discuss the problem of the external standpoint with references to the works of Thomas Nagel, John McDowell, and Thompson Clarke, and argue against a quietest reading according to which the problem of the external standpoint is nonsensical and resolves itself. In the second step, I transpose L.A. Paul's notion of 'epistemically transformative experience' from decision theory to the realm of philosophical practice and argue that the incomprehensible notion of the 'external standpoint' can be reinterpreted as a rhetorical means that evokes such experiences. In the third step, finally, I discuss Stanley Cavell's idea of a 'truth of skepticism' and Duncan Pritchard's notion of 'epistemic vertigo' against this background.

\section{The Incomprehensibility of the 'External Standpoint' and the Quietist Objection}

Skepticism is a very old tradition in philosophy and it is impossible to capture all varieties of skepticism in a single statement of what is characteristic of it. There are different kinds of skeptical arguments like the modes of Pyrrhonism, the modes of Agrippa, the Academic skeptics' critique of Stoic epistemology, or the various arguments given by early modern skeptics. However, a crucial feature of many accounts of modern skepticism is the quest for absolute objectivity. In what follows, I will focus on the corresponding skeptical problem of an 'external standpoint' capable of affording us an 


\section{Transformative Experience in Skepticism}

absolutely objective perspective on ourselves and the world. In his influential paper 'The Legacy of Skepticism', Thompson Clarke distinguishes 'plain' from 'philosophical' questions against the background of this perspective: 'The truth is, I think, that this simple quest for absolute objectivity drives us beyond the plain, moving us to philosophize' (Clarke, 1972, p. 762). The concept of absolute objectivity that stands behind the drive to philosophize is then elucidated by referring to a standpoint that makes the world into an object. This standpoint is an external standpoint compared to the plain standpoint within the world: 'Certain intuitive philosophers I respect say that in philosophizing we stand back and treat the world in its entirety as an object apart from us, whereas as plain men we are "inside the world" (ibid.). ${ }^{1}$ While there are other ways of defining objectivity, I will focus in what follows on the notion of an external standpoint, which, indeed, belongs to the standard notions of objectivity. It has been labeled, for example, the 'absolute conception of reality' by Bernard Williams (cf. Williams 1978) or the 'view from nowhere' by Thomas Nagel (cf. Nagel 1986). As Barry Stroud points out in his comments on Clarke's paper, however, this notion of objectivity immediately leads to skepticism, since we cannot obtain an external standpoint outside of the world (Stroud, 2000, pp. 30-31).

Thomas Nagel discusses an even deeper problem of the notion of 'absolute objectivity': Following Nagel, this notion is not consistently thinkable. He argues that absolute objectivity is 'naturally described' (Nagel, 1986, p. 67) in terms of the metaphor of a 'view from nowhere' and that this view, in order to be absolutely objective, would have to be assessed by another view, which leads to a regress of perspectives. This regress puts the very concept of absolute objectivity into question. In the words of Thomas Nagel:

However often we may try to step outside of ourselves, something will have to stay behind the lens, something in us will determine the resulting picture, and this will give grounds for doubt that we are really getting any closer to reality. The idea of objectivity thus seems to undermine itself. The aim is to form a conception of reality which includes ourselves and our view of things among its objects, but it seems that whatever forms the conception will not be included by it (p. 68).

1 Clarke might be alluding to Cavell here. This is, at least, what Cavell indicates in the foreword of his Claim of Reason (Cavell, 1979, p. xxv). 


\section{Rico Gutschmidt}

It is a fascinating tension in Nagel's book that he explores the idea of a philosophical quest for objectivity by way of transcending ourselves (pp. 74-77) although he also argues that we cannot conceive the notion of objectivity: 'The most familiar scene of conflict is the pursuit of objective knowledge, whose aim is naturally described in terms that, taken literally, are unintelligible: we must get outside of ourselves, and view the world from nowhere within it' (p. 67). Following this line of thought, the problem is not that we cannot attain objectivity, as Stroud argues in his above-mentioned comments on Clarke. Rather, the problem is that the very notion of 'objectivity' is not comprehensible in the first place.

A related argument can be found in a 1981 paper by John McDowell, ${ }^{2}$ where he introduces his concept of a view from 'sideways on'. This concept represents in a similar way the notion of a view from outside of our everyday or plain practices. As McDowell puts it, a scientific explanation should be '[...] recognizable from an objective standpoint, conceived in terms of the notion of the 'view from sideways on' - from outside any practices or forms of life partly constituted by local or parochial modes of response to the world' (McDowell, 1998, p. 214). McDowell discusses the sideways-on view in the context of Wittgenstein's arguments about rule-following. In particular, he relates the view from sideways on to the position of platonism in philosophy of mathematics. Now, just as Nagel argues that the view from nowhere is not consistently thinkable, so McDowell claims that the platonic picture of the sideways-on view is inconceivable: 'But this picture has no real content' (p. 208). According to McDowell, we think that we understand this metaphor only because we actually think that we can have the view from sideways on: 'We cannot occupy the independent perspective that platonism envisages; and it is only because we confusedly think we can that we think we can make any sense of it' (ibid.). Furthermore, while Nagel is still pursuing the quest for absolute objectivity by way of transcending ourselves, McDowell argues that this is impossible for conceptual reasons. The very notion of 'absolute objectivity' is an illusion: 'But one strand in Wittgenstein's thought about 'following a rule' is that the source of the temptation is the desire for a security that would actually be quite illusory' (p. 203).

This reference resembles the therapeutic and resolute readings of Wittgenstein. According to those readings, Wittgenstein's philosophy elucidates performatively that certain philosophical concepts are nonsensical. This particularly applies to the concept of a view

2 Non-Cognitivism and Rule-Following, reprinted in McDowell 1998. 


\section{Transformative Experience in Skepticism}

from nowhere, as Alice Crary points out. With respect to the concept of an external viewpoint on language, Crary summarizes the therapeutic readings of Wittgenstein by claiming that according to these readings, Wittgenstein's '[...] fundamental aim is to get us to see that the point of view on language we aspire to or think we need to assume when philosophizing - a point of view on language as if outside from which we imagine we can get a clear view of the relation between language and the world - is no more than the illusion of a point of view' (Crary, 2000, p. 6).

With respect to the argument of Nagel that I presented above and following the judgment of McDowell and the therapeutic readings of Wittgenstein, the philosophical quest for the perspective of an external standpoint of absolute objectivity seems to be misguided, since the very notion of such a standpoint is confused and illusory. Accordingly, the skeptical problem of absolute objectivity seems to be dissolved, which can be understood as an example of a quietist conclusion that brings us back to where we began. We just realize that the quest for absolute objectivity is misguided and acquiesce in our everyday life. In this context, quietism refers to the idea that we first live in our everyday practices and then get puzzled by philosophy. We can be cured of these puzzlements only by another philosophical practice that dissolves the initial philosophical problems in such a way that we finally understand that we have been simply confused. Then everything returns to the way it was before: we are back in our everyday practices without philosophical confusions. ${ }^{3}$ This kind of quietism is often ascribed to ancient Pyrrhonism, which is usually understood as a philosophical practice that aims to free us from confused philosophical dogmatism in order to lead to a state of tranquility. In twentieth-century philosophy, quietist positions can be found in the ordinary-language philosophy of, for example, J.L. Austin, and in several attempts of dissolving skepticism. ${ }^{4}$ Not least, Wittgenstein claims in his Philosophical Investigations that he aims at a dissolution of philosophical confusions in such a way that '[...] philosophical problems should completely disappear' (Wittgenstein, 2009, §133). As Duncan Pritchard reads this statement, for Wittgenstein, '[...] philosophy is both the malaise and the cure' (Pritchard, 2011, p. 201). For Pritchard, Wittgenstein is

3 Cf. e.g. Virvidakis 2008 for a more detailed discussion of quietist positions.

4 Cf. e.g. McGinn 1989 and Williams 1991. Recent attempts to dissolve skepticism can be found in Pritchard 2016, Schönbaumsfeld 2016, and Kern 2017. 


\section{Rico Gutschmidt}

thus a quietist in the above-mentioned sense and can be related to Pyrrhonism in this respect, since, in the words of Pritchard, as the result of Wittgenstein's philosophical practice '[...] we are returned to where we began; we cannot make progress with philosophy. But of course in a very real sense Pyrrhonians are also quietists' (ibid.).

However, while I agree that the notion of an 'external standpoint' is theoretically confused and that the corresponding skeptical problem of absolute objectivity can thus be dissolved, I think that the insight into the incomprehensibility of an external standpoint should not just lead to a quietist acquiescence in common life, but can embody a new, albeit non-propositional, understanding of the finitude of the human condition. This understanding is not captured by the statement that we cannot have an absolutely objective perspective on the world, since we cannot even coherently think of such a 'view from nowhere'. Instead, I think that the experience of the failure of the attempt to conceive the idea of an 'external standpoint' can lead to vertiginous experiences that are epistemically transformative with respect to our finitude. According to this transformative reading of the skeptical problem of an external standpoint, the skeptic does not hold the claim or position that an absolute perspective is impossible, since this itself would be a claim purporting to come from an absolute perspective. Instead, Nagel's argument can be interpreted as a performative undermining of the notion of an external standpoint, as it were, 'from within'. The crucial point of this reinterpretation is that the experience of this undermining can be epistemically transformative since it is able to bring about a new way of being and seeing. This is not to be understood as a form of knowledge, but rather as a new attitude that acknowledges the incomprehensibility of the notion of the external standpoint and thereby, as I will argue in the fourth part of the paper, embodies an experiential, non-propositional insight into our finitude. This transformative reading of the skeptical problem of an external standpoint is in line with the theoretical dissolution of the problem of absolute objectivity, but still goes beyond quietism, since the experience of this dissolution can lead to a new mode of being and seeing that differs profoundly from our previous 'plain' self-understanding; we are, then, not returned to where we began. Such transformation can happen abruptly, as in the case of a Wittgensteinian switch of aspect. Jean-Philippe Narboux, for example, points out that the difference between the 'plain' and the 'philosophical' in Clarke's reading of skepticism can be understood as a respective switch of aspect (Narboux, 2014, p. 180), which certainly is a kind of experience. 


\section{Transformative Experience in Skepticism}

Beyond that, Clarke explicitly expresses the necessity of such a new 'understanding' of our finitude with respect to the incomprehensibility of an external standpoint. First, like Nagel and McDowell, Clarke shows in the above-mentioned paper that there is a problem with the very notion of 'absolute objectivity'. In a first step, he refers to the classical skeptical scenario of Descartes' Meditations that suggests that we might be deceived by an evil demon. Clarke argues that the evil demon might be deceived by another demon, which leads to a regress of perspectives. For Clarke, this is a shortcoming of Descartes' skeptical scenario: 'Does Descartes's possibility even seem to make sense, if we ask ourselves how the Evil Demon, or God, could know that he, too, wasn't dreaming - and allow that neither could?' (Clarke, 1972, p. 766) However, this does not impair the power of the skeptical scenario, as, for example, Barry Stroud points out: 'Must we suppose that the evil demon, or some being lurking somewhere in the wings, knows, or even could know, what is really going on? Again, it seems to me the answer is "No"" (Stroud, 2000, p. 36). But Clarke still points to a regress of perspectives that, in a second step, implies that no outsider can know our real, objective situation because we can always think of a further exterior; every outsider is, thus, in Clarke's words 'in the same boat' with us (p. 766). This strongly resembles Nagel's argument that also points to a regress of perspectives and thereby shows that the metaphor of the 'view from nowhere' is inconceivable. As Nagel, Clarke concludes that we do not know what the notion of 'absolutely objective knowledge' is supposed to mean. In terms of his above-quoted distinction between plain and philosophical questions, Clarke argues that if we ask the skeptical question 'Are we awake now, or dreaming?' as a philosophical question (p. 761), i.e. as a question that asks for absolute objectivity, we can answer this question neither positively nor negatively due to the corresponding regress of perspectives (p. 768). Accordingly, this 'philosophical' question as well as the corresponding quest for absolute objectivity are misguided.

While this indeed dissolves the skeptical problem of absolute objectivity, I do not think that Clarke wanted to dissolve this problem in a quietist way. This is how Barry Stroud reads Clarke: 'So the Philosophical Question is in some way phoney or illegitimate. That is the central point of Clarke's rejection of philosophical skepticism and of the philosophical search for absolute objectivity' (Stroud, 2000 , p. 34). Against that, I think that there is more going on in Clarke's paper than a quietist dissolution. Of course, it is not entirely clear what exactly Clarke is arguing for, since the paper is extremely dense and somewhat hermetic. But I think that my understanding of 


\section{Rico Gutschmidt}

Clarke is a plausible way to read his paper. ${ }^{5}$ In the last passages, Clarke argues that although '[s]kepticism frees us from antiquated problems, including itself', it nonetheless '[offers] us a new, challenging problem' (p. 769). On my reading, this indicates that even though the skeptical problem of absolute objectivity can be dissolved at the theoretical level, this is not the end of the story. Instead, Clarke points out at the very end of his paper that '[s] kepticism leaves us the problem of the plain, of its structure, the character and source of its relative 'non-objectivity" (ibid.). On my reading, this is an expression of the problem of the finitude of the human condition, or, to borrow some of Clarke's terminology, the problem of our self-understanding as plain beings. As I read it, Clarke argues that the incomprehensibility of the notion of 'absolute objectivity' calls into question the concept of the 'plain' in a way that still needs to be explored. More precisely, I think that the 'challenging problem' that skepticism offers us is the problem of understanding the finitude of the 'plain' human condition against the background of the incomprehensibility of an external standpoint. The incomprehensibility of this notion should not just turn us to a quietist acquiescence in common life, but transform our way of being and seeing profoundly.

In this respect, I think that L.A. Paul's concept of 'epistemically transformative experience' can be fruitfully transposed from decision theory to the problem of skepticism. Accordingly, I will argue in the rest of the paper with reference to this concept that the failure of the attempt to comprehend the notion of absolute objectivity can evoke vertiginous and ground-shaking experiences that are epistemically transformative. On my reading, the experiential insight that is gained through these experiences can be understood as a response to the 'new, challenging problem' that, for Clarke, constitutes the legacy of skepticism.

\section{Transformative Experience and Philosophical Practice}

In her recent book on decision theory, L.A. Paul points out that there are certain experiences in life that transform our self-understanding in ways that we cannot anticipate before having had them, as, for

5 Although Clarke's philosophical ideas were highly influential, particularly on Cavell and Stroud, there is very little secondary literature devoted to Clarke. It was only in 2019 that an English monograph was written on Clarke, including the first close reading in the literature of Clarke's hermetic but seminal paper, cf. Eichorn 2019. 


\section{Transformative Experience in Skepticism}

example, becoming a parent, fighting as a soldier in a war, or starting a career as a doctor (Paul, 2014, pp. 5-15). This initiated a debate in decision theory regarding the problem of making a rational decision in cases in which we cannot evaluate the potential results of a decision without having had the experience that follows from having already made the decision (cf. e.g. Arvan 2015 and Pettigrew 2015). For the purpose of this paper, however, it suffices to focus on the very notion of 'transformative experience'. Paul argues that there are two kinds of transformative experience: 'They can be epistemically transformative, giving you new information in virtue of your experience. And they can be personally transformative, changing how you experience being who you are' (p. 17). She then says that she is focusing in her book on experiences that are both epistemically and personally transformative and that she uses the notion of 'transformative experience' as referring to those experiences: 'Having a transformative experience teaches you something new, something that you could not have known before having the experience, while also changing you as a person' (ibid.). However, when she talks of information and knowledge here, she is not thinking of ordinary theoretical knowledge, but rather of some kind of experiential knowledge. More precisely, she illustrates the idea of epistemic transformation with reference to the thought-experiments of Thomas Nagel (pp. 5-6) and Frank Jackson (pp. 8-15). In this context, she employs the notion of knowing what it is like to be in certain experiential states (p. 11) and is thus alluding to a form of non-propositional knowledge. Even though a transformative experience does not necessarily include new propositional knowledge, it can still be epistemically significant, since we perceive ourselves and the world differently through a personal transformation and we then know, albeit non-propositionally, what it is like to be in this experiential state.

Now, the central point of this paper is that the notion of 'epistemically transformative experience' can be fruitfully transposed from decision theory to experiences that are evoked by the philosophical practice of skepticism. I will not provide a rigorous definition of the notion of 'philosophical practice' though. In the context of this paper, it suffices to say that this notion expresses the idea that different kinds of philosophical reasoning can evoke transformative or nontransformative experiences in many ways. On my reading, however, a philosophical transformation implies not only knowledge of what it is like to have a certain philosophical experience, but also, as a consequence, a new way of seeing the corresponding philosophical problem. While this new way of conceiving a philosophical problem is linked to the knowledge of what it is like to have the 


\section{Rico Gutschmidt}

experience, it embodies a form of non-propositional insight that is best understood not in terms of knowledge, but in terms of coming to hold a new attitude toward the philosophical issue at stake. My point is that Paul's conjunction of personal and epistemic transformation shows that philosophical experiences can eventuate in such new, albeit non-propositional, philosophical insights. In a way, the corresponding interdependence of experience and understanding can already be found in ancient philosophy. In his introduction to Hadot's Philosophy as a Way of Life, Arnold Davidson, for example, refers to Hadot's concept of 'spiritual exercises' and quotes Hadot as saying, 'These exercises are certainly exercises of meditation, but they do not only concern reason; in order to be efficacious, they must link the imagination and affectivity to the work of reason, and therefore all the psychagogical means of rhetoric' (Hadot, 1995 , p. 23). ${ }^{6}$ This can be understood as an example of the conjunction of personal and epistemic transformation, and I think that the incoherent metaphor of the 'view from nowhere' and the incomprehensible notion of 'absolute objectivity' can be reinterpreted as such rhetorical means.

To begin with, even though these notions are incoherent or incomprehensible, they are not sheer nonsense. It does not make sense when taken literally, but the notion of, for example, the 'external standpoint' can still be understood metaphorically. It is a spatial metaphor that is transposed from everyday contexts to the problem of skepticism. This is what Stanley Cavell calls the 'projection of a word' (Cavell, 1979, pp. 180-190). In his Must We Mean What We Say?, Cavell discusses the anti-skeptical strategy that therapeutic and quietist readings ascribe to Wittgenstein, namely the claim that the skeptic is misusing language: 'And now comes the objection: The skeptic uses a form of words that makes perfect sense in certain contexts and then applies it to a case in which it makes no sense' (Cavell, 1976, p. 250). Against that, Cavell argues - with Wittgenstein's philosophy of language in the background - that the words of the skeptic are still intelligible to a certain extent even when they are projected to a new context: 'The problem with this objection is that it cuts two ways: it does show that the skeptic is shifting contexts, but it also

6 Hadot generally claims that ancient philosophy ' $[. .$.$] even if it is ap-$ parently theoretical and systematic, is written not so much to inform the reader of a doctrinal content but to form him' (Hadot, 1995, p. 64). He elucidates this, for example, with respect to '[...] the works of Plotinus and Augustine, in which all the detours, starts and stops, and digressions of the work are formative elements' (ibid.). 


\section{Transformative Experience in Skepticism}

shows why what he says is intelligible. (If not fully, still not fully not.) That these words are not ordinarily used in such contexts doesn't mean they can't naturally be given application in them' (ibid.). In fact, this is how language works anyhow: 'Using language depends on this ability to give application in new contexts' (ibid.). Hence, although the concept of an absolutely detached external standpoint is, strictly speaking, incomprehensible, it can still be understood as a conceptual projection to the context of skepticism.

As another example, the totality of the world also is, strictly speaking, incomprehensible, since we cannot conceive of such a totality. In this context, the problem is not a regress of perspectives, but rather the paradoxes of infinity (cf. e.g. Grim 1991, Priest 2002, and Williamson 2003). However, if we project the concept of 'totality' from special contexts to the whole world, there is something that we do understand about it and we can meaningfully use this concept in philosophy. This is what Hans Blumenberg calls 'absolute metaphors'. Blumenberg points out that although the totality of the world cannot be comprehended, it is still possible to envision it with the help of special images: 'Although it has been idle, ever since Kant's antinomies, to make theoretical assertions about the totality of the world, the quest for images to 'stand in' for this objectively unattainable whole is by no means a trifling matter' (Blumenberg, 2010, p. 15). This also applies to the spatial metaphors of the 'view from nowhere' or the 'external standpoint'. Although they are not fully understandable, we can naturally give them an application in philosophical discourse (Cavell). As absolute metaphors (Blumenberg), they represent the notion of objectivity and thus give rise to the skeptical problem of the external standpoint. ${ }^{7}$ This notion is, thus, not fully understandable, but also not fully not.

At the theoretical level, however, this notion is incoherent. Now, with respect to its metaphorical significance, I want to suggest that the problem of absolute objectivity can be reinterpreted as a means of rhetoric that rests on the metaphorical understanding of that problem and that evokes the philosophical experience of failing to understand it fully. My point, then, is that this experience transforms

7 A similar point can be found in the theory of metaphors in philosophy of science. 'Heuristic metaphors' are supposed to explore new contexts in science, cf. Black 1962 and Hesse 1963. Also, Paul Ricoeur uses metaphors in a quite similar way, cf. Ricoeur 1975. Not least, according to the 'conceptual metaphor thesis' by George Lakoff, metaphors generally are basic vehicles for our understanding of the world and ourselves, cf. e.g. Lakoff/ Johnson 1980 . 


\section{Rico Gutschmidt}

our self-understanding in a significant way and that, thus, a philosophical problem that is nonsensical at the theoretical level can still be philosophically relevant.

However, before I discuss the notion of 'absolute objectivity' in this respect, I will briefly elucidate this point with reference to Leibniz's question, 'Why is there anything at all and not rather nothing?' Carl Gustav Hempel, for example, argues that Leibniz's question does not make sense because we cannot even think of an answer (Hempel, 1973, p. 200). ${ }^{8}$ But Hempel concedes that although the question is a 'logical impossibility', it nonetheless leads to the experience of wonder about the fact of existence (pp. 201-202). ${ }^{9}$ Of course, in a way, there is no reason to wonder at the fact of existence, since the question is nonsensical in the end. But in terms of our philosophical self-understanding as finite beings, the unexplainable fact of existence is of the utmost importance; even though the corresponding question is a 'logical impossibility', it has a strong significance, albeit at a metaphorical level. In asking this question, we are somewhat confused, because we cannot even think of an answer. But this is an important confusion that is not simply resolved when we unmask the nonsensical character of the question that evoked the confusion. Instead, we understand ourselves differently after having struggled with it. As a result of failing to fully understand the fact of existence, we see the world in a new way, albeit in a non-propositional mode: We now wonder at its existence. As a matter of fact, this is one of the examples of Wittgenstein's notorious notion of running up against the limits of language: 'Man has the urge to thrust against the limits of language. Think for instance about one's astonishment that anything exists. This astonishment cannot be expressed in the form of a question and there is no answer to it. Anything we can say must, a priori, be only nonsense. Nevertheless we thrust against the limits of language' (oral statement, documented in Waismann, 1965, pp. 12-13). For Wittgenstein, too, the fact of existence leads to the experience of wonder, even though the problem is nonsensical at the theoretical level: 'And I will now describe the experience of wondering at the existence of the world by saying: it is the experience of seeing the world as a miracle' (Wittgenstein, 1965, p. 11). This definitely is a new way of seeing the world, which not only includes the knowledge of what it is like to be in this experiential state, but, at the same time, also yields a non-propositional understanding of the

8 He discusses this, of course, from the perspective of his deductivenomological model of explanation.

9 In this context, Hempel refers to sentence 6.52 of the Tractatus. 


\section{Transformative Experience in Skepticism}

fact of existence, i.e. a new way of being and seeing with respect to the incomprehensibility of the fact that anything exists. I thus think that this is an example of an epistemically transformative experience that is philosophically significant. Stanley Cavell explicitly admits that he has had the experience that Wittgenstein talks about (Cavell, 1979, p. 241), and he also claims that it was part of Wittgenstein's teaching to evoke such experiences (p. 15). In Cavell's terms, Leibniz's question reveals the mystery of the existence of the world (ibid.). What is more, he relates this mystery not only to Wittgenstein and Heidegger, but also to his concept of a 'truth of skepticism':

An admission of some question as to the mystery of the existence, or the being, of the world is a serious bond between the teaching of Wittgenstein and that of Heidegger. The bond is one, in particular, that implies a shared view of what I have called the truth of skepticism, or what I might call the moral of skepticism, namely, that the human creature's basis in the world as a whole, its relation to the world as such, is not that of knowing, anyway not what we think of as knowing. (ibid.)

Hence, for Cavell, the experience of the mystery of existence leads to a new 'basis in the world as a whole' for the human creature. For Wittgenstein, this means seeing the world as a miracle; for Cavell, this means that the relation of the human creature to the world is not a relation of knowledge. Either way, the crucial point is that the philosophical practice of dealing with a seemingly nonsensical problem yields a new perspective on the world.

\section{The External Standpoint, Reconsidered}

Now, I think that the problem of absolute objectivity can be reinterpreted in a similar way. Although we understand the metaphors of the 'view from nowhere' or of the 'external standpoint' to a certain extent, we do not understand them fully. However, as the struggle with the seemingly nonsensical question of Leibniz leads to a new way of seeing the world, I will now argue that the philosophical struggle with these metaphors and the failure of understanding them fully can also yield a transformative experience toward a new basic attitude. For a start, Cavell's notion of a 'truth of skepticism' describes such new relation to the world and others in terms of an attitude of acceptance or acknowledgment (cf. e.g. Cavell, 1988, p. 109). I am not claiming though that the experience of skepticism necessarily leads to acceptance or acknowledgment. Someone could experience the 


\section{Rico Gutschmidt}

skeptical problem of the external standpoint but instead adopt an attitude of denial or rejection. We could also just as well feel frustrated, bored, angry, or sad when we contemplate our own finitude. However, on my reading, Cavell's point is that we always already accept or acknowledge the world and others without being aware of it. It is only through the skeptical experience that we recognize this aspect of the human condition. Hence, while an attitude of denial or rejection might also be epistemically transformative, I think that only the attitude of acceptance or acknowledgment reflects the human condition adequately. Without discussing the problem of human psychology of whether we should expect this attitude to arise, my claim is that it is only through this attitude that we understand the finitude of the human condition in an adequate way. Moreover, this is a non-propositional form of understanding that is linked to the corresponding transformative experience, since the original philosophical problem depends on the incoherent metaphors of the 'view from nowhere' or of the 'external standpoint'. To put it more simply, confronting the skeptical problem of absolute objectivity leads us to experience something, and the experience itself cannot be communicated or construed as a proposition or a claim. It still is an important experience that includes a new way of being and seeing. The central point of my paper is that the status of this non-propositional understanding is best understood if one interprets Cavell's attitude of acknowledgment as the result of a philosophical experience that is epistemically transformative in L.A. Paul's sense. Accordingly, I think that Cavell's concept of a 'truth of skepticism' can be regarded as partly an answer to the 'challenging problem' that according to Thompson Clarke - at least on my reading - embodies the legacy of skepticism: We have to understand ourselves as finite or plain beings against the background of the incomprehensibility of an external standpoint. However, Cavell's 'truth of skepticism' is not a straightforward 'solution' of Clarke's problem at the theoretical level, since the corresponding 'insight' is not achieved by theoretical reasoning alone. Beyond theoretical reasoning, it is linked to an attitude that is the result of an epistemically transformative experience. I do think, though, that Clarke's 'challenging problem' can only be 'solved' in this way, which still is more than a quietist dissolution of skepticism.

To support this claim, I now turn more closely to the philosophical experiences that can be evoked by skepticism in more general terms. To begin with, the philosophical experience of wonder that I referred to above seems to be a rather positive sentiment. However, in Plato and Aristotle, the moment of wonder (thaumazein) was decidedly a 


\section{Transformative Experience in Skepticism}

troubling experience. Accordingly, the experiences that are evoked by skepticism are usually somewhat negative. David Hume, for example, describes the existential dimension of skepticism in his Treatise of Human Nature, where he concedes that all his skeptical enquiries lead him to 'philosophical melancholy and delirium' (Hume, 2007a, p. 175). In his book on Wittgenstein, Saul Kripke reports, albeit very briefly, that he had 'something of an eerie feeling' when he contemplated the skeptical paradox that he found in the Philosophical Investigations (Kripke, 1982, p. 21). Similarly, Cavell claims that the insight into the finiteness of our knowledge makes the world uncanny to us. It belongs to Cavell's afore-mentioned concept of a 'truth of skepticism' that we have to find a new way of trusting to the world and others as a result of skeptical disturbances. As Cavell puts it in his lecture on the 'Uncanniness of the Ordinary': 'The return of what we accept as the world will then present itself as a return of the familiar, which is to say, exactly under the concept of what Freud names the uncanny. That the familiar is a product of a sense of the unfamiliar and of the sense of a return means that what returns after skepticism is never (just) the same' (Cavell, 1988, p. 100). As I have argued above, I think this is best understood as a transformative experience that results in a new attitude that is linked to a new self-understanding with respect to the finiteness of our knowledge. Similarly, when Hume leaves his study and returns to everyday life, he is even able to laugh about the skeptical threat (Hume, 2007b, p. 117), but he also argues that skepticism demonstrates ' $[\ldots]$ the whimsical condition of mankind, who must act and reason and believe; though they are not able, by their most diligent enquiry, to satisfy themselves concerning the foundation of these operations, or to remove the objections, which may be raised against them' (ibid.). Of course, Hume's return to everyday life can be interpreted in a quietist way according to which philosophy and skepticism leave ordinary life more or less the same, while the whimsical condition of mankind is acknowledged at the theoretical level. However, I think that Hume's impressive description of the experiential aspect of skepticism shows that skepticism can evoke transformative experiences that lead to a new attitude in which we acknowledge our finiteness in Cavell's sense.

Beyond Hume's general skepticism, the particular whimsicality of the incomprehensibility of an external standpoint can also evoke transformative experiences. To begin with, Cavell claims that the skeptical insight into the groundlessness of our everyday practices is terrifying: 


\section{Rico Gutschmidt}

That on the whole we do ['make, and understand, the same projections' of 'words... into further contexts'] is a matter of our sharing routes of interest and feeling, senses of humor and of significance and of fulfillment, of what is outrageous, of what is similar to what else, what a rebuke, what forgiveness, of when an utterance is an assertion, when an appeal, when an explanation - all the whirl of organism Wittgenstein calls 'forms of life'. Human speech and activity, sanity and community, rest upon nothing more, but nothing less, than this. It is a vision as simple as it is difficult, and as difficult as it is (and because it is) terrifying. (Cavell, 1969, p. 52)

In his above-quoted paper, John McDowell refers to this passage and claims that the terrifying insight into the finitude of all the mentioned human practices leads to vertigo: 'The terror of which Cavell writes at the end of this marvelous passage is a sort of vertigo, induced by the thought that there is nothing that keeps our practices in line except the reactions and responses we learn in learning them. The ground seems to have been removed from under our feet' (McDowell, 1998, p. 207). A similar vertiginous experience can already be found in Descartes, who refers at the beginning of his Second Meditation to the ground-shaking effect of his skeptical enquiry:

So serious are the doubts into which I have been thrown as a result of yesterday's meditation that I can neither put them out of my mind nor see any way of resolving them. It feels as if I have fallen unexpectedly into a deep whirlpool which tumbles me around so that I can neither stand on the bottom nor swim up to the top. (Descartes, 1996, p. 16)

Not least, in his recent book, Duncan Pritchard discusses the existential dimension of skepticism and also points to the experience of vertigo. He refers to the idea of an external standpoint and claims that the desire to have an absolutely detached perspective is quite natural (Pritchard, 2016, p. 187). A similar argument can be found in Cavell, who claims, for example, in 'Declining Decline': 'I mean to say that it is human, it is the human drive to transcend itself, make itself inhuman, which should not end until, as in Nietzsche, the human is over' (Cavell, 1989, p. 57). The desire to detach from the plain whirl of organism and the longing for an external standpoint seems to be part of the human condition. With respect to the problem of skepticism, in On Certainty, Wittgenstein introduces the notion of 'hinge propositions' that form a basic structure of our plain practices. According to the above-mentioned therapeutic readings, 


\section{Transformative Experience in Skepticism}

Wittgenstein's point is to show that they cannot be grounded from an external standpoint and that, moreover, the skeptical demand for such an external foundation is misguided. Now, Pritchard attempts to refute skepticism with reference to Wittgenstein's hinge propositions, which he takes to provide a sufficient foundation of our knowledge from within our practices. But he also concedes that the insight into the finitude of our epistemic practices, as opposed to the aspiration to achieve an external foundation of our knowledge, induces vertigo: 'I call this psychological state epistemic vertigo $[\ldots]$ in order to capture the idea that it is essentially a kind of phobic reaction to one's epistemic predicament' (Pritchard, 2016, p. 6).

However, neither McDowell nor Pritchard speak of a transformation toward a new attitude in Cavell's sense. On my reading, though, the experience of vertigo that they are alluding to can be interpreted as part of an epistemically transformative experience that yields a new basic relation toward the world. In particular, while I agree that the theoretical longing for an external standpoint is indeed misguided, I think that the corresponding skeptical problem can be reinterpreted as a rhetorical means that evokes vertiginous transformative experiences. According to this line of thought, the philosophical struggle with the incomprehensible notion of an 'external standpoint', or, more precisely, the failure of the attempt to fully comprehend this notion, is epistemically transformative and can yield a new way of being and seeing with respect to the finitude of the human condition. This failure is not just a personal failure, but stems from the arguments of Nagel, McDowell, and Wittgenstein that I presented above. Also, it differs from the failure of grasping complex concepts like, for example, string theory, since it concerns a fundamental aspect of the human condition and not just, say, specific theories of physics. All in all, the experiential aspect that McDowell and Pritchard mention underpins my transformative reinterpretation of the skeptical problem of an external standpoint. Even though the experiences reported by Descartes, Hume, and Kripke are not explicitly transformative, they certainly can give rise to a transformation and, thus, fit into this reading as well. Not least, I agree with Cavell's above-mentioned claim that Wittgenstein wanted to evoke such experiences and that he thus was not a quietist, let alone a foundationalist (cf. Gutschmidt forthcoming).

Finally, I want to elucidate my claim by contrasting it to a kind of experience that Barry Stroud discusses in his book Engagement and Metaphysical Dissatisfaction. Without referring to transformative experience, Stroud indicates in this book that there might be 'a different 


\section{Rico Gutschmidt}

kind of philosophical understanding of ourselves' that results from the fact that we are unable to achieve the external standpoint that metaphysics demands (Stroud, 2011, p. 18). On Stroud's reading, the goal of metaphysics basically is what Clarke labelled the 'philosophical' as opposed to the 'plain', namely the answer to the question '[...] whether things really stand in the world in the ways we think we have good reason to believe they do' (p. 1). In other words, for Stroud, metaphysics asks for absolute objectivity. He concludes that the insight into the impossibility of gaining this form of objectivity - or, more precisely, the insight into the reason why we cannot gain this form of objectivity - yields a 'second-level satisfaction':

If it could be shown that no metaphysical satisfaction is possible in the way we seek it, and we could understand why that is so, that itself could be a significant fact about the human condition. It would not give us what metaphysical reflection seemed to promise, but it might provide a certain reflective or secondlevel satisfaction of its own. We would recognize that we seek a certain kind of detached understanding of ourselves and the world that we also can see we can never achieve. (p. 160)

In a way, Stroud also describes a transformative experience here, namely the transformation of metaphysical dissatisfaction into second-level satisfaction. However, this is not quite the kind of transformative experience that I have discussed here. As in his abovequoted comments on Clarke, Stroud seems to assume that there is an external standpoint and that we just cannot attain it, whereas, for example, the experience of epistemic vertigo that Duncan Pritchard describes belongs to the epistemic predicament that comes into view as a result of the insight that this standpoint is not even conceivable. Hence, although Stroud's concept of 'secondlevel satisfaction' can be interpreted as referring to an epistemically transformative experience, it is about a rather weak transformation that accepts the impossibility of achieving an absolutely detached standpoint. Against that, the experiential transformation I am aiming at goes deeper, since the recognition that an outside-of-ourworld is not even conceivable shows that this concept is nonsensical at the theoretical level. The crucial point is that this recognition, then, evokes an experience that is epistemically significant by yielding a new way of being and seeing with respect to the incomprehensibility of this concept. As I have argued above, Cavell's concept of a 'truth of skepticism' can be interpreted as such transformation, and the corresponding transformative reading of the skeptical problem of an external standpoint is supported by the experiential aspect of skepticism 


\section{Transformative Experience in Skepticism}

that is highlighted in the works of Descartes, Hume, Kripke, McDowell, and Pritchard. Even though these authors do not explicitly mention a transformation in the sense of this paper, I think that the experiences they describe do have the power to be transformative.

\section{Open Conclusion: The Finitude of the Human Condition}

As a conclusion, I briefly want to discuss the notion of the finitude of the human condition. I have quoted above that Hume points to the 'whimsical condition of mankind' that we have to accept and, with reference not only to Wittgenstein, but also to Kant and Heidegger, Cavell argues that the limits of our knowledge belong to the human condition: 'Both Wittgenstein and Heidegger continue, by reinterpreting, Kant's insight that the limitations of knowledge are not failures of it' (Cavell, 1979, p. 241). However, according to Cavell, we are usually not aware of these limits and thus unaware of our finite nature. Accordingly, I want to suggest that it is the task of the philosophical practice of skepticism to disrupt our everyday practices and to thereby point to the limits of our self-understanding. This resembles the phenomenological notion that we understand something new about our everyday practices in the very moment of a disruption of these practices. Cavell relates this notion to skepticism:

Something very similar is what I want to say in formulating my abiding interest in material object skepticism - that what skepticism questions or denies my knowledge of $i$ the world of objects I inhabit, is the world. As elsewhere, the abnormal provides our access to the normal. I recognize from the failure of what skepticism regards as my knowledge of objects what it is my everyday life with objects consists in. (p. 448)

The central point of my paper is that the status of this recognition can be conceived of as the result of epistemically transformative experiences that are evoked by the philosophical practice of skepticism. In compliance with Paul's conjunction of personal and epistemic transformation, this practice leads to a new attitude that accepts the limits of reason and at the same time yields a non-propositional understanding of these limits, i.e. a new way of being and seeing with respect to the incomprehensibility of an external standpoint. In particular, this transformative reading of the skeptical problem of absolute objectivity goes beyond a quietist dissolution of this problem. The 


\section{Rico Gutschmidt}

corresponding experiences can be troubling, since the world might become uncanny and we might feel vertiginous; but as Cavell also points out, this must not lead to despair (p. 237). It is, after all, an important part of the skeptical tradition from Pyrrhonism via Hume to Wittgenstein and Cavell that we get back to everyday life, transformed, but not desperate or despairing.

Not least, I think that the transformative experience of the skeptical problem of an external standpoint is essential to our self-understanding as finite human beings. As we have seen, Cavell and Pritchard, for example, argue that the longing for an external standpoint is part of our nature as human beings. Against that, McDowell proposes that we should try to snuff out this desire in order to avoid the experience of vertigo:

Now if we are simply and normally immersed in our practices, we do not wonder how their relation to the world would look from outside them, and feel the need for a solid foundation discernible from an external standpoint of view. So we would be protected against the vertigo if we could stop supposing that the relation to reality of some area of our thought and language needs to be contemplated from a standpoint independent of that anchoring in our human life that makes the thoughts what they are for us. (McDowell, 1998, p. 211)

But he also admits in a footnote to this passage that ' $[\mathrm{t}] \mathrm{his}$ is not an easy recipe. Perhaps finding out how to stop being tempted by the picture of the external standpoint would be the discovery that enables one to stop doing philosophy when one wants to' (ibid.). ${ }^{10}$ Obviously, he is alluding to the position of quietism, according to which the insight into the incomprehensibility of the notion of an external standpoint just dissolves the problem and leaves us immersed in our practices without being bothered anymore about our lack of objective knowledge. Against that, I have argued in this paper that the failure of the attempt to understand the notion of an external standpoint leads to vertiginous experiences and, as a result, to an experiential understanding of the finitude of the human condition. In this regard, the attempt to gain an external standpoint is not just a human drive, but rather a necessary step to achieving an adequate understanding of the human condition. It is only through the failure of the attempt to transcend our finitude that we become fully aware of this very finitude, albeit in a non-propositional, experiential way.

10 This is a reference to $\$ 133$ of Wittgenstein's Philosophical Investigations that I mentioned in the second part of this paper. 


\section{Transformative Experience in Skepticism}

What is more, this kind of transformative understanding does not come to an end. We do not undergo a skeptical transition once and for all. Instead, this form of understanding is bound to the performance of the skeptical practice and cannot be separated from it. Sextus Empiricus, for example, claims that skeptics do not know that knowledge is impossible, but that they are 'still investigating' in this matter (PH I 3, cf. Sextus, 2000, p. 3). Similarly, Wittgenstein struggled with philosophical problems until his death; he did not come to a quietist rest. Accordingly, the epistemically transformative experiences that are evoked by the practice of philosophy do not conclusively resolve our puzzlements about the human condition. Although I think that certain transformative experiences in philosophy reveal the finitude of the human condition, this does not provide a stable, permanent state of peace of mind. Instead, the philosophical struggle with this finitude is an ongoing, potentially endless, task. Of course, the struggle with our finitude nonetheless allows us to be immersed in our practices: I am not saying that one should, or even can, face the vertiginous abyss of the view from nowhere all the time. But we understand adequately that we are immersed in our everyday practices only if we try - unavailingly - to transcend them. Hence, the never-ending struggle with the vertiginous step 'outside' is an important part of our humanity. ${ }^{11}$

\section{References}

Marcus Arvan, 'How to Rationally Approach Life's Transformative Experiences', Philosophical Psychology, 28(2015), 1199-1218.

Max Black, Models and Metaphors. Studies in Language and Philosophy (Ithaca: Cornell University Press, 1962).

Hans Blumenberg, Paradigms for a Metaphorology (Ithaca: Cornell University Press, 2010).

11 I thank the Volkswagen Foundation for a Post-doctoral Fellowship at the University of Chicago and Jason Bridges and James Conant for the course on Barry Stroud's philosophy that I attended. I am also grateful to the audience of the conference 'Skepticism as a Form of Philosophical Experience' at the University of Chicago (February 2017) where I first presented the ideas that finally led to this paper. It was particularly helpful to discuss these ideas with Barry Stroud on this occasion. I owe an enormous debt to Roger Eichorn for numerous fruitful conversations about the status of skepticism and for his comprehensive treatment of my drafts. Not least, I want to thank two anonymous reviewers for their comments on an earlier version of this paper. 


\section{Rico Gutschmidt}

Stanley Cavell, Must we mean what we say? A Book of Essays (New York: Scribner, 1969).

Stanley Cavell, The Claim of Reason (Oxford: Oxford University Press, 1979).

Stanley Cavell, In Quest of the Ordinary. Lines of Skepticism and Romanticism (Chicago: University of Chicago Press, 1988).

Stanley Cavell, 'Declining Decline', in: Idem This New Yet Unapproachable America. Lectures after Emerson after Wittgenstein (Albuquerque: Living Batch Press, 1989), 29-76.

Thompson Clarke, 'The Legacy of Skepticism', Fournal of Philosophy, 69/ 20 (1972), 754-769.

Alice Crary, 'Introduction', in: R. Read \& A. Crary (Eds.) The New Wittgenstein (London: Routledge, 2000), 1-18.

René Descartes, Meditations on First Philosophy (J. Cottingham ed.) (Cambridge: Cambridge University Press, 1996).

Roger E. Eichorn, Philosophy and Everyday Life. Thompson Clarke and the Legacy of Skepticism (Dissertation, University of Chicago, 2019).

Patrick Grim, The Incomplete Universe (Cambridge, MA: MIT Press, 1991).

Rico Gutschmidt, 'Beyond Quietism. Transformative Experience in Pyrrhonism and Wittgenstein', International Fournal for the Study of Skepticism (forthcoming).

Pierre Hadot, Philosophy as a Way of Life (Oxford: Blackwell, 1995).

Carl G. Hempel, 'Science Unlimited?', The Annals of the Fapan Association for Philosophy of Science, 14 (1973), 187-202.

Mary Hesse, Models and Analogies in Science (London: Sheed and Ward, 1963).

David Hume, A Treatise of Human Nature (D.F. Norton and M.J. Norton ed.) (Oxford: Oxford University Press, 2007a).

David Hume, An Enquiry concerning Human Understanding (P. Millican ed.) (Oxford: Oxford University Press, 2007b).

Andrea Kern, Sources of Knowledge: On the Concept of a Rational Capacity for Knowledge (Cambridge, MA: Harvard University Press, 2017).

Saul A. Kripke, Wittgenstein on Rules and Private Language (Cambridge, MA: Harvard University Press, 1982).

George Lakoff \& Mark Johnson, Metaphors We Live By (Chicago: University of Chicago Press, 1980).

John McDowell, 'Non-Cognitivism and Rule-Following', in: Idem Mind, Value, and Reality (Cambridge, MA: Harvard University Press, 1998), 198-218.

Marie McGinn, Sense and Certainty. A Dissolution of Scepticism (Oxford: Blackwell, 1989).

Thomas Nagel, The View from Nowhere (Oxford: Oxford University Press, 1986).

Jean-Philippe Narboux, 'Thompson Clarke's Tightrope Walk', International Fournal for the Study of Skepticism, 4 (2014), 153-188. 


\section{Transformative Experience in Skepticism}

Laurie A. Paul, Transformative Experience (Oxford: Oxford University Press, 2014).

Richard Pettigrew, 'Transformative Experience and Decision Theory', Philosophy and Phenomenological Research, 91 (2015), 766-774.

Graham Priest, Beyond the Limits of Thought (Oxford: Oxford University Press, 2002).

Duncan Pritchard, 'Wittgensteinian Pyrrhonism', in: Machuca, D. E. (Ed.) Pyrrhonism in Ancient, Modern, and Contemporary Philosophy (Dordrecht: Springer, 2011), 193-202.

Duncan Pritchard, Epistemic Angst: Radical Skepticism and the Groundlessness of Our Believing (Princeton: Princeton University Press, 2016).

Paul Ricoeur, La Métaphor Vive (Paris: Seuil, 1975).

Genia Schönbaumsfeld, The Illusion of Doubt (Oxford: Oxford University Press, 2016).

Sextus Empiricus, Outlines of Scepticism (J. Annas and J. Barnes trans.) (Cambridge: Cambridge University Press, 2000).

Barry Stroud, Understanding Human Knowledge (Oxford: Oxford University Press, 2000).

Barry Stroud, Engagement and Metaphysical Dissatisfaction (Oxford: Oxford University Press, 2011).

Stelios Virvidakis, 'Varieties of Quietism', Philosophical Inquiry, 30/1-2 (2008), 157-175.

Friedrich Waismann, 'Notes on Talks with Wittgenstein', The Philosophical Review, 74 (1965), 12-16.

Bernard Williams, Descartes: The Project of Pure Enquiry (London, New York: Routledge, 1978).

Michael Williams, Unnatural Doubts. Epistemological Realism and the Basis of Scepticism (Oxford: Blackwell, 1991).

Timothy Williamson, 'Everything', Philosophical Perspectives, $17 / 1$ (2003), $415-465$.

Ludwig Wittgenstein, 'Lecture on Ethics', The Philosophical Review, 74 (1965), 3-12.

Ludwig Wittgenstein, Philosophical Investigations (P.M.S. Hacker and J. Schulte trans.) (Oxford: Wiley-Blackwell, 2009).

RICO GUTSCHMIDT (ricogutschmidt@gmail.com) currently works as an assistant professor at the University of Konstanz. His philosophical research encompasses such diverse fields as philosophy of physics, Heidegger and negative theology, Wittgenstein and skepticism, and, most recently, philosophical reasoning as transformative experience. 